\title{
Electrochemical Characteristics of Azo Dyes Doped Poly(3,4-Ethylenedioxythiophene)
}

\author{
Cigdem Dulgerbaki ${ }^{1}$ (D), Ali Ihsan Komur ${ }^{2}{ }^{(D)}$, Esin Eren ${ }^{2,3}$ (D), Volodymyr V. Tkach ${ }^{4}$ (D), Olga V. \\ Skrypska $^{4}$ (D) , Marta V. Kushnir ${ }^{4}$ (D), Yana G. Ivanushko 4 (D), Petro I. Yagodynets 4,*iD, Aysegul Uygun \\ Oksuz 2,*iD
}

1 Alanya Alaaddin Keykubat University, Faculty of Engineering, Department of Engineering Fundamental Sciences, 07450 Alanya, Antalya, Turkey

2 Suleyman Demirel University, Faculty of Arts and Science, Department of Chemistry, 32260 Isparta, Turkey

3 Suleyman Demirel University, Innovative Technologies Application and Research Center, Department of Energy Technologies, 32260 Isparta, Turkey

4 Chernivtsi National University, General and Material Chemistry Department, 58001, Kotsyubynsky Str. 2, Chernivtsi, Ukraine

* Correspondence: ved1988mid@ rambler.ru (P.I.Y.); aysegul.uygun@yahoo.com (A.U.O.);

Scopus Author ID 55866651400 (P.I.Y.); 56200685500 (A.U.O.)

Received: 22.05.2020; Revised: 26.05.2020; Accepted: 26.05.2020; Published: 1.06.2020

\begin{abstract}
In the present study, the electrosynthesis and the electrochemical characterization of azo dyes doped poly(3,4-ethylenedioxythiophene (PEDOT) were described. PEDOT film was electrochemically deposited onto indium doped tin oxide (ITO) coated/glass electrode, following azo dyes adsorption. The electropolymerized-PEDOT films on ITO glass were doped with various azo dyes; 4-Phenylazo2-phenyliminomethyl-phenol (PAPM), 4-Phenylazo-2-(p-tolyimino-methyl)-phenol (PATM) and 4[(2-Hydroxy-5-phenylazo-benzylidene)-amino]-benzenesulfonic acid (HPAB). The structures of azo dyes-doped PEDOT were characterized via cycle voltammograms and electrochemical impedance spectroscopy (EIS). Diverse doping counterions have a significant influence on the electrochemical behaviour of electropolymerized-PEDOT film. The electropolymerized-PEDOT doped by HPAB (PEDOT-HPAB) film possesses higher electrochemical activity than other azo dye-doped PEDOT composites. The main characteristics of PEDOT-azo dyes films contain uniformity, durability, and adherent on ITO electrodes, which are better when it is compared to PEDOT film.
\end{abstract}

Keywords: Azo dyes; PEDOT; Thin film; electrochemical.

(C) 2020 by the authors. This article is an open-access article distributed under the terms and conditions of the Creative Commons Attribution (CC BY) license (https://creativecommons.org/licenses/by/4.0/).

\section{Introduction}

Conducting polymers (CPs) are a novel kind of functional materials, and they have gained significant attention in various application areas due to their lightweight, workability, corrosion resistance, cheap cost, and superior electrical, mechanical, optical, and conducting features [1-5]. They are regarded as to be remarkable polymers that can behave as conductors, semiconductors, superconductors, and magnetic compounds. As a general property, CPs are characterized by a broad bandgap and the presence of $\pi$-electron backbone or conjugation that are liable for their unique features. However, most CPs exhibit weak processability, which leads to restrictions in their application areas. Thus, many scientific researches have focused on improvement in processability without compromising electronic and chemical features [6]. Especially, dye incorporated conducting polymers (DCPs) proceed to draw attention for a lot of researchers because of their practical application areas in the growth and the structure of 
novel materials such as sensors, photovoltaic devices, artificial muscles, and displays [7]. Great influences on improvements in processability and features have been attained by way of functionalization of the CPs via the preparation of CPs [8], copolymerization [9], and composite [10] using molecular dopant. Various compounds, including simple inorganic acids [11], micro-organic compounds (sulfonic acids and dyes) [12], were used as dopants.

Among diverse conducting polymers, poly(3,4-ethylenedioxythiophene) (PEDOT) has been utilized as a significant component in many applications with different shapes and geometries because of its high conductivity, simple to polymerize, its high durability in air, as well as at relatively high temperatures $[13,14]$. When the electrode surface is modified with PEDOT, the electrochemical behaviors of the modified electrode can be improved importantly, which enlarges its application in electrochemical catalysis and sensing [15]. However, how to achieve more effective electrodeposition and more influential catalytic behavior of PEDOT, maintains a significant problem [15]. To solve this problem, some doping agents have been used to improve electronic and chemical features. As literature shows, doping PEDOT with admirable, functional compounds to prepare a composite has been successfully confirmed [1517]. For example, Soares et al. studied the electrochemical processes at the electrode/electrolyte interface of PEDOT:PSS, polystyrene sulfonate, modified electrodes. Electrochemical Impedance Spectroscopy (EIS) was used to evaluate the adsorption and electrochemical influences caused via interaction of catechol at the conductive substrate. The modified electrode showed a high electrochemical response and vigorous interactions with an analyte, which lead to the improvement of diverse ways of transduction based on electrochemical reactions and alteration in the $\mathrm{R}_{\mathrm{ct}}$ values, potentializing the construction of either electrochemical or impedimetric sensor [16]. In another study, neural electrodes have been deposited with electrodeposited PEDOT doped with chondroitin sulfate. Their results indicated that the influential electrode area and charge injection capability were remarkably smaller than formerly used dopants containing para-toluene sulfonate (pTs), dodecylbenzenesulfonate (DBSA), etc. [18].

The Azo dyes are very distinct and well obviously described kind, characterized by the presence of one or more Azo $(-\mathrm{N}=\mathrm{N}-)$ groups. Azo dyes give bright hues with high intensity. Their common structural characteristic is the azo chromophore $(-\mathrm{N}=\mathrm{N}-)$, usually associated with auxochromic hydroxyl(-OH) or amino groups(- $\left.\mathrm{NH}_{2}\right)$. The dyes exhibit benzenoid quinonoid tautomerism with the corresponding quinone hydrazones [19, 20]. 4-Phenylazo-2phenyliminomethyl-phenol (PAPM), 4-Phenylazo-2-(p-tolyimino-methyl)-phenol (PATM) and 4-[(2-Hydroxy-5-phenylazo-benzylidene)-amino]-benzenesulfonic acid (HPAB) from azo family are chosen for this study.

In recent years, the obtained results demonstrate that dye molecules as anion dopants lying perpendicularly between the polymer chains enable the mass carrying at the polymer film and enhance the degree of order as compared with the prepared polymer using common ions. These characteristics supply better electronic charge carrying in the bulk phase in such a way that the system, including dye, provides a higher photocurrent density under polychromatic illumination and a faster response time when compared to that of the system without dye [21].

Various studies demonstrated that dye molecules could be incorporated into the CPs during synthesis to supply improved optical properties. Koshido et al. [22] have investigated the characteristics of CPs doped with photochromic dyes and showed that the photoluminescence and photoconductivity of the polymers are increased. Electrical and optical features of soluble dye/conducting polymer (DCPs) composites were evaluated by Feng et al. 
[23]. The results demonstrated that the polymers containing dye indicated enhanced performances in relation to charge separation and transfer.

The dye incorporated conducting polymers were bigger, smoother, and were convenient to protonation and deprotonation as well as redox reaction [24]. The indigo carmine incorporated PPY is informed to have improved electrochromic performances, higher photocurrent density, and more rapid response time when it is compared to undoped PPY. The influences of the dye incorporated CPs can be summarized - (i) Changes the electrical and optical features by contributing to enhance the performance of the charge separation and transfer; (ii) functions as a molecular dopant during the preparation of the soluble polymers; (iii) dye's functional molecules can be incorporated into the polymer to enhance its features and increase selectivity; (iv) dyes are widely known of acceleration the reaction as the surfactants [25].

In this work, azo dye-doped PEDOT composites were prepared by electrochemical polymerization. Among conducting polymers, poly(3,4-ethylenedioxythiophene) (PEDOT) was selected because of its superior features in a lot of basic categories such as low oxidation potential, excellent durability to air exposure, electrochemical stability and rapid switching response [26]. The influence of the doping function of organic dyes on the electrochemical features of the composites is discussed in detail.

\section{Materials and Methods}

\subsection{Materials.}

3,4-ethylenedioxythiophene (EDOT) was obtained from Acros Chemicals. Tetrabutylammonium hexafluorophosphate $\left(\mathrm{TBAPF}_{6}\right)$ and Acetonitrile $(\mathrm{ACN})$ was purchased from Fluka. Lithium perchlorate $\left(\mathrm{LiClO}_{4}\right)$ and Propylene Carbonate (PC) were supplied from Merck. All reagents were used as received without further purification. Indium tin oxide (ITO) coated glass was used as a working electrode and cleaned with ethanol and deionized water prior to use.

\subsection{The electropolymerization of PEDOT and adsorption of azo-dyes.}

The dye synthesis has been realized at Chernivtsi National University (Ukraine). The ethanol, butanol, 5-phenylazosalicylic aldehyde, and correspondent amines were used from the deposit of Chernivtsi National University without purification. The NMR characterization was realized at Varian Inova $400 \mathrm{mHz}$ equipment at Enamine (Kiev).

The electrochemical synthesis was carried out by a Gamry 300 potentiostat/galvanostat interfaced to PC computer system. In a three-electrode cell configuration, ITO coated glass as a working electrode, a platinum $(\mathrm{Pt})$ wire as a counter electrode, an $\mathrm{Ag} / \mathrm{AgCl}$ with $3 \mathrm{M} \mathrm{KCl}$ as a reference electrode were used. For EDOT polymerization, the three-electrode system was put in the electrolyte containing $0.1 \mathrm{M} \mathrm{LiClO}_{4} / \mathrm{ACN}$ and $1 \mathrm{M}$ EDOT, performing with potentiostatic method at a constant potential of $1.4 \mathrm{~V}$ with a charge density of $30 \mathrm{mC} \mathrm{cm}^{-2}$ at room temperature. After polymerization, PEDOT film was immersed in the azo dye solution containing $3 \mathrm{mM}$ azo-dye in $0.1 \mathrm{M} \mathrm{TBAPF}_{6} / \mathrm{ACN}$ for one hour. Azo dyes were adsorbed on the surface of the PEDOT film on ITO glass. Pure PEDOT film was electrochemically synthesized at the parallel conditions without azo dye adsorption as a comparison sample. 


\subsection{Electrochemical and Optical Characterization.}

Cyclic voltammetry measurements were performed with a Gamry 300 potentiostat/galvanostat. ITO coated glass as a working electrode, a platinum $(\mathrm{Pt})$ wire as a counter electrode, an $\mathrm{Ag} / \mathrm{AgCl}$ with $3 \mathrm{M} \mathrm{KCl}$ as a reference electrode were used. The chargetransfer processes of PEDOT-azo dyes thin films were studied using electrochemical impedance spectroscopy. EIS was carried in a three-point electrode similar to the one used in $\mathrm{CV}$ in an electrolytic cell of $1 \mathrm{M} \mathrm{LiClO}_{4} / \mathrm{PC}$ in a frequency range of $0.01-10^{5} \mathrm{~Hz}$ and at an $\mathrm{AC}$ amplitude of $5 \mathrm{mV}$ at room temperature with a CHI760E electrochemical analyzer. Nyquist plots were extracted from this spectroscopy. These graphs showed capacitance behaviors of thin films. Investigation of the optical absorption properties was performed using a UV-Vis spectrophotometer LOMO (USSR) in the region of 230-340 nm. Chemical structures and molecular weight of dyes used for the study are shown in Table 1.

Table 1. Chemical structures and molecular weight of dyes used for the study.

\begin{tabular}{|c|c|c|}
\hline DYE & Chemical Structure & Molecular weight (g/mol) \\
\hline PAPM & & 301 \\
\hline PATM & & 315 \\
\hline HPAB & & 381 \\
\hline
\end{tabular}

PAPM synthesis: The mixture of 1,13 $\mathrm{g}(0,005 \mathrm{~mol})$ of 5-phenylazosalicylic aldehyde with $0,47 \mathrm{~g}(0,005 \mathrm{~mol})$ of aniline in $20 \mathrm{ml}$ of butanol has been refluxed for 2 hours. When the solution was cooled, the deposit formed was filtered out, rinsed by ether, and dried. Yield 0,84 г (56 \%). Melting point $136-137{ }^{\circ} \mathrm{C}$ (ethanol). Found, \%: C 76,05; H 4,72; N 13,77. C19H15N3O. Calculated, \%: C 75,73; H 5,02; N 13,94.

PATM synthesis: The mixture of 1,13 g (0,005 mol) 5-phenylazosalicylic aldehyde with i $0,54 \mathrm{~g}(0,005 \mathrm{~mol})$ of 4-methylaniline in $20 \mathrm{ml}$ of butanol was refluxed for 1,5 hours. After cooling the solution, the deposit was filtered out, rinsed by ether, and dried. Yield: 1,19 g (76 \%). Melting point: $129-130{ }^{\circ} \mathrm{C}$ (Ethanol). Found, \%: C 76,05; H 5,62; N 13,57. $\mathrm{C}_{20} \mathrm{H}_{17} \mathrm{~N}_{3} \mathrm{O}$. Calculated, \%: C 76,17; H 5,43; N 13,32.

HPAB synthesis: The mixture of 1,13 г (0,005 mol) 5-phenylazosalicylic aldehyde with $0,86 \mathrm{~g}(0,005 \mathrm{~mol}) 4$-aminobenzenesulfonic acid in $35 \mathrm{ml}$ of butanol has been refluxed for 2 hours. The deposit was filtered out and rinsed by ether. Yield 1,40 г (74\%). Melting point $-343{ }^{\circ} \mathrm{C}$ (ethanol). Found, \%: C 60,05; H 3,72; N 10,87. C19H15N3O4S. Calculated, \%: C 59,83; H 3,96; N 11,02.

IR spectrum: $\left(\mathrm{KBr}, \mathrm{cm}^{-1}\right): 1620(-\mathrm{CH}=\mathrm{N}), 1494(-\mathrm{N}=\mathrm{N}-)$.

\section{Results and Discussion}

The optical properties of the azo dyes were investigated by UV/Vis spectroscopy in the range of 230-340 nm. The absorption spectra of the studied compounds are shown in Figure 1. UV-Vis spectroscopic investigations of PAPM, PATM, and HPAB solutions were performed 
to evaluate the behavior of substituent patterns on the absorption properties of azo dye. All dye molecules exhibited absorbance in the UV (200-300 $\mathrm{nm}$ ) region. The absorption maxima of an aqueous solution of PAPM and PATM were found at $294 \mathrm{~nm}$ and $290 \mathrm{~nm}$, respectively (Figure 1). With the addition of the methyl group, the absorbance intensity is increased significantly due to the hyperchromic shift; the maximum absorbance of 0.84 at $290 \mathrm{~nm}$ is noted. The introduction of electron-donating groups into the azo dyes causes a hyperchromic shift. When the functional group is sulfonic acid as in the case of HPAB structure, the absorbance decreases as 0.44 at $292 \mathrm{~nm}$, so the hypochromic shift is noted with the presence of strong electronwithdrawing group [27].

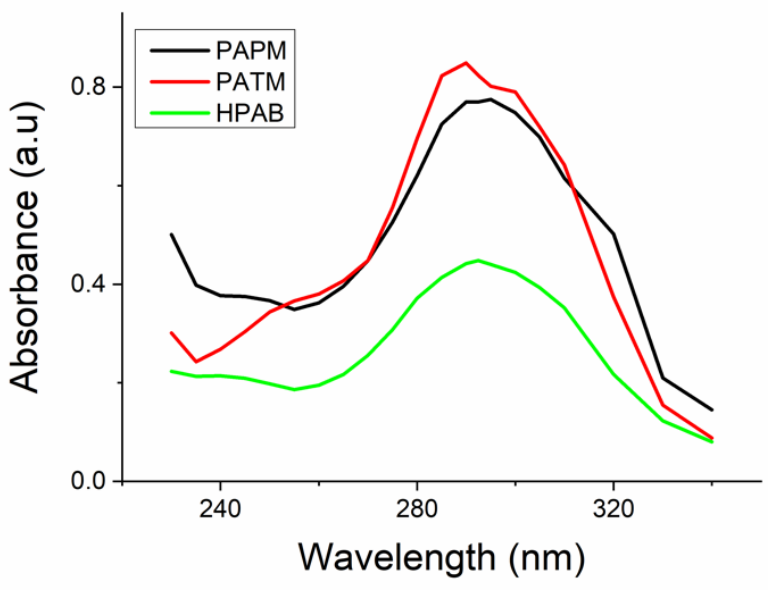

Figure 1. Absorption spectra of azo dyes PAPM, PATM, and HPAB.

Cyclic voltammograms of PEDOT and azo-dye doped PEDOT composites with the potential range from $-0.5 \mathrm{~V}$ to $1.0 \mathrm{~V}$ at a scanning rate of $100 \mathrm{mV} / \mathrm{s}$ are shown in Figure 2 . Diverse doping counterions have a significant influence on the electrochemical behavior of electropolymerized-PEDOT film. Figure 2 showed that the CV curves of PEDOT-azo dyes are quite dissimilar from pure PEDOT as a consequence of azo dye being present [28]. As shown in Figure 2, there are significant differences in the magnitudes of the peak current depending on the type of dopant used. This result suggests that azo dyes have a marked effect on the electrochemical behavior of PEDOT [29]. According to Fig 3(a-d) including repetitive 20 cycles test, the CV curves were quite similar. Still, they showed stable peak currents, demonstrating that the PEDOT-azo dye films were coated tightly and uniformly and had perfect electrochemical durability [30]. The oxidation peak current densities of the PEDOT/PAPM, PEDOT/PATM, and PEDOT/HPAB are significantly higher than that of PEDOT film. These facts confirmed that azo dye-doped PEDOT composites are more electrochemically active, which demonstrated a much more rapid reaction rate on PEDOT-azo dye electrodes. PEDOT/HPAB shows the highest current density of all the composites. Large azo dyes containing the azo unit and functional groups as dopant affected the molecular structure, morphology and electrochemical performance of PEDOT. From SEM analysis, it can be seen that HPAB was helpful in the formation of loose granular morphology with some clear channels. This morphology was convenient for the increase of $\pi$-conjugated degree and surface area of PEDOT/HPAB for taking part in a redox reaction. Thus it was conductive to increasing the electrochemical activity of PEDOT as in the case of PEDOT doped with congo red also containing azo unit and sulfonate anions [31]. 


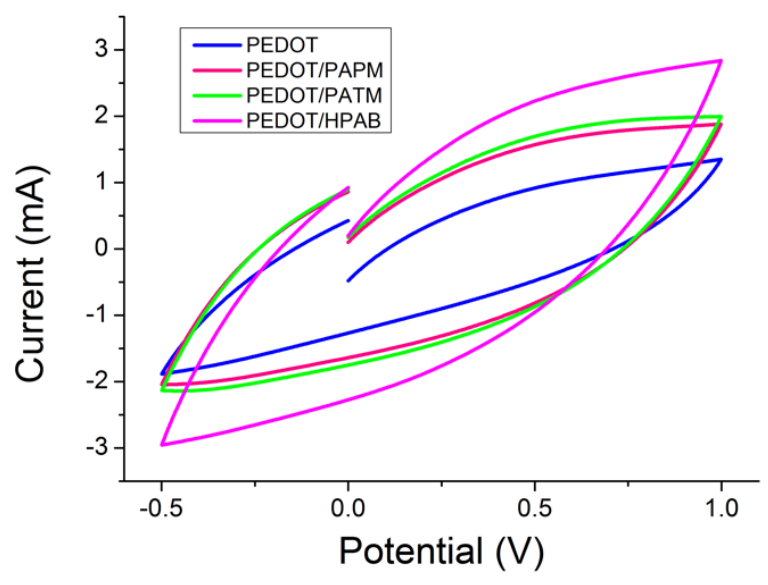

Figure 2. Cyclic voltammograms of PEDOT, PEDOT/PAPM, PEDOT/PATM and PEDOT/HPAB.



Figure 3a. Consecutive $20 \mathrm{CV}$ s of PEDOT electrode in $1 \mathrm{M} \mathrm{Li-PC}$ solution.

The reason for the increase of current values in cyclic voltammograms of PEDOT/HPAB could be explained by its special molecular structure and loose granular morphology with some clear channels. Firstly, a large molecular volume of HPAB caused an increase in the $\pi-\pi$ stacking distance of the aromatic rings of PEDOT, which was advantageous for the entrance of electrolyte into the active substance. Secondly, the HPAB molecules with $\pi$-conjugated structure were conductive to the transition of $\pi$-conjugated electrons between neighboring PEDOT chains and the enhancement of $\pi$ - conjugated degree of PEDOT [32]. Thirdly, the loose granular morphology with some clear channels of PEDOT/HPAB was favorable for the rapid diffusion of electrolyte and the full contact of electrolyte with the active substance, which was confirmed by the CV curves of PEDOT/HPAB.

The mechanism of the redox process of azo dyes onto PEDOT film might be explained as it was hypothesized that the azo dyes could diffuse from the inside to the PEDOT surface, occurring transfer complex with PEDOT skeleton via $\pi-\pi^{*}$ interactions [33], as demonstrated via $\mathrm{CV}$ graphs that the area of cyclic voltammograms was increased after the introduction of the azo dyes especially HPAB. The strong electrostatic interaction between the sulfonate group of azo dye with negative charges and PEDOT molecules with positive charges can be formed for PEDOT/HPAB film. This interaction can lead to improved electrochemical performance. 


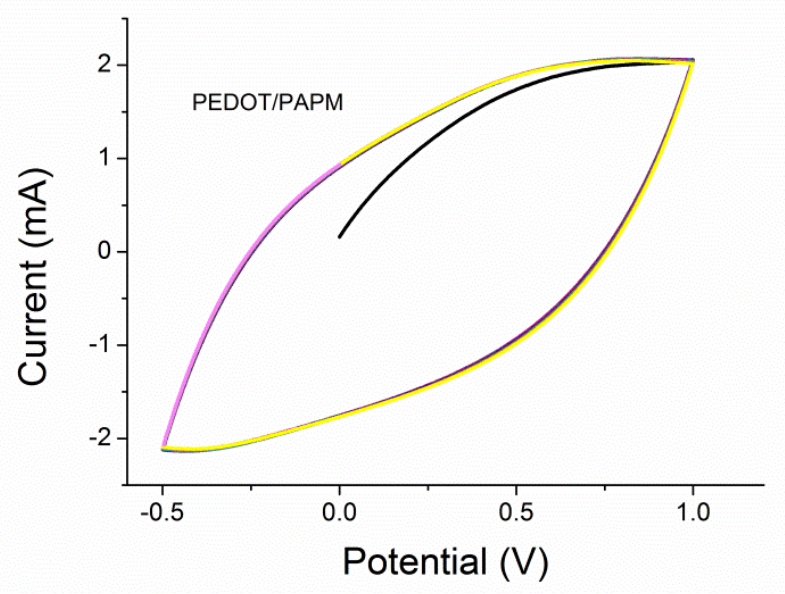

Figure 3b. Consecutive $20 \mathrm{CVs}$ of PEDOT/PAPM electrode in $1 \mathrm{M}$ Li-PC solution

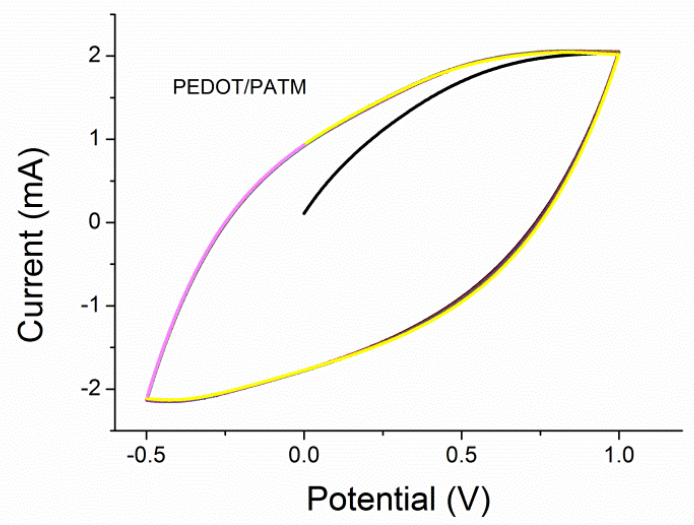

Figure 3c. Consecutive $20 \mathrm{CV}$ s of PEDOT/PATM electrode in $1 \mathrm{M}$ Li-PC solution

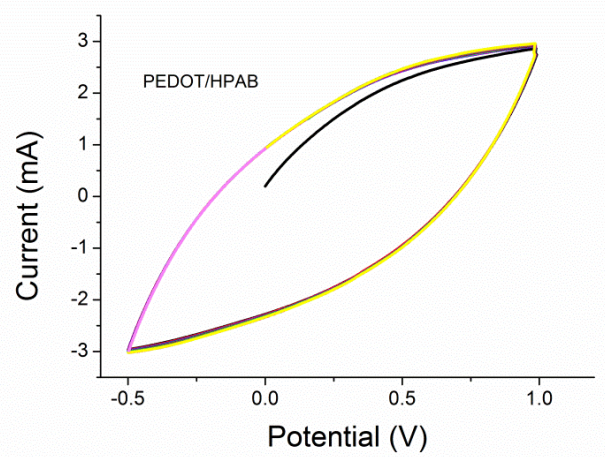

Figure 3d. Consecutive $20 \mathrm{CV}$ s of PEDOT/HPAB electrode in $1 \mathrm{M} \mathrm{Li}$-PC solution

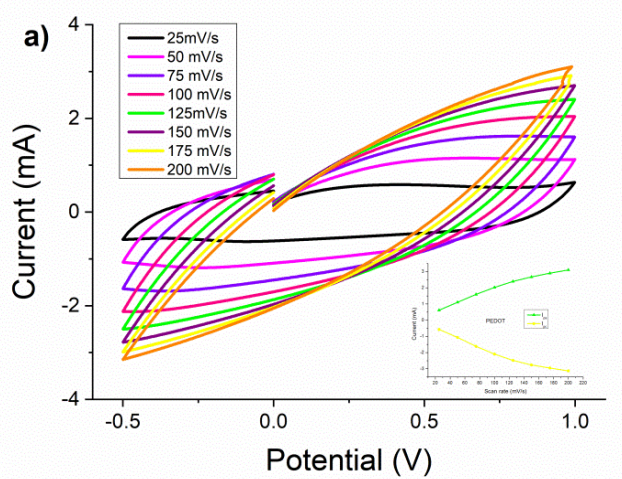

Figure 4a. Cyclic voltammograms of PEDOT at different scan rates; peak current versus scan rate for the anodic and cathodic branches of the two processes (inset). 


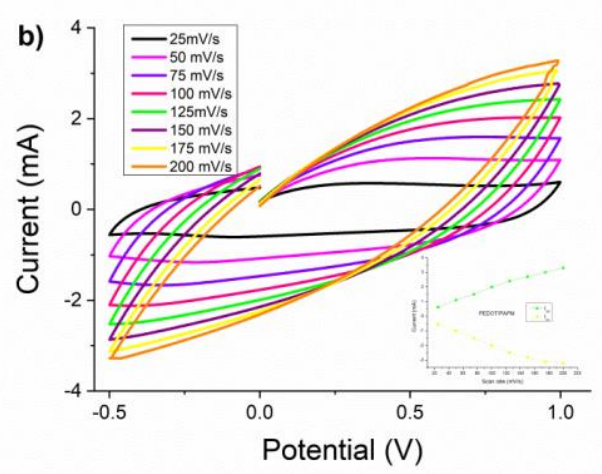

Figure 4b. Cyclic voltammograms of PEDOT/PAPM at different scan rates; peak current versus scan rate for the anodic and cathodic branches of the two processes (inset).

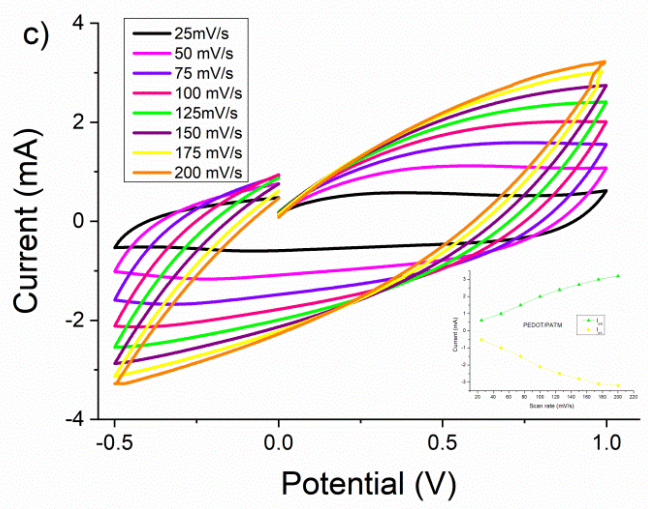

Figure 4c. Cyclic voltammograms of PEDOT/PATM at different scan rates; peak current versus scan rate for the anodic and cathodic branches of the two processes (inset).

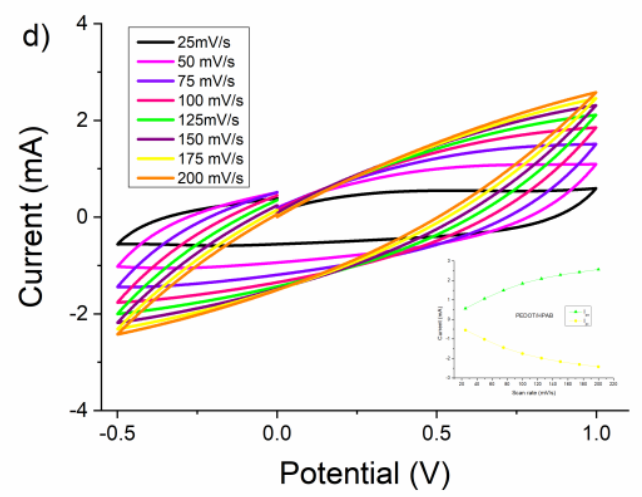

Figure 4d. Cyclic voltammograms of PEDOT/HPAB at different scan rates; peak current versus scan rate for the anodic and cathodic branches of the two processes (inset).

Redox behaviors of the PEDOT-azo dyes composites were investigated using cycling potential between neutral and oxidized states at diverse scans in the monomer free $\mathrm{LiClO}_{4}-\mathrm{PC}$ electrolyte medium. It is clear that with the rise of the scanning rate from $25 \mathrm{mV} \mathrm{s}^{-1}$ to $200 \mathrm{mV}$ $\mathrm{s}^{-1}$, the oxidation potential is increased, and the reduction potential decreased.

Figure 4 showed that the peak current was directly proportional to the scan rate, pointing out that the composite films were electroactive and well-adhered to the conductive electrode surfaces [34]. The anodic and cathodic peak currents display a linear dependence as a function of the scan rate, as shown in the insets of Fig. 4. As a result, the migration of the electroactive species is not diffusion-controlled and reversible in the range of $25-200 \mathrm{mV} \mathrm{s}^{-1}$ [35]. 
Electrochemical impedance spectroscopy (EIS) is a useful measurement to characterize the significant interfacial charge transfer and diffusion processes inside electrodes [36]. Electrochemical impedance spectroscopy (EIS) was scanned in a frequency range of $0.01-10^{5}$ $\mathrm{Hz}$ and at an $\mathrm{AC}$ amplitude of $5 \mathrm{mV}$ at room temperature with a $\mathrm{CHI} 760 \mathrm{E}$ electrochemical analyzer. Figure 5 shows the Nyquist plots of the PEDOT, PEDOT/PAPM, PEDOT/PATM, PEDOT/HPAB films. It was clear that each Nyquist plot was contained a semicircle in the high-frequency region and a straight line in the low-frequency region. The semicircle of the Nyquist plots gives charge transfer resistance $\left(\mathrm{R}_{\mathrm{ct}}\right)$ at PEDOT/electrolyte and PEDOT/azodye/electrolyte interface. The $\mathrm{R}_{\mathrm{ct}}$ at the interface between the electrode and the electrolyte could be approximately calculated by the diameter of curvature along the $\mathrm{X}$-axis in the Nyquist plot [36]. The $R_{c t}$ value greatly depended on the conducting capability of active material, and the superior conductivity of active material could obviously facilitate the electron transfer at the interface between the electrode and the electrolyte and decrease the $R_{c t}$ value [31]. As seen in Figure 5, The $\mathrm{R}_{\mathrm{ct}}$ of the films followed the order: PEDOT/PATM > PEDOT/PAPM > PEDOT $>$ PEDOT/HPAB. The $R_{c t}$ values were calculated as $\sim 107,116,129,101 \Omega$ for PEDOT, PEDOT/PAPM, PEDOT/PATM, PEDOT/HPAB films, respectively.

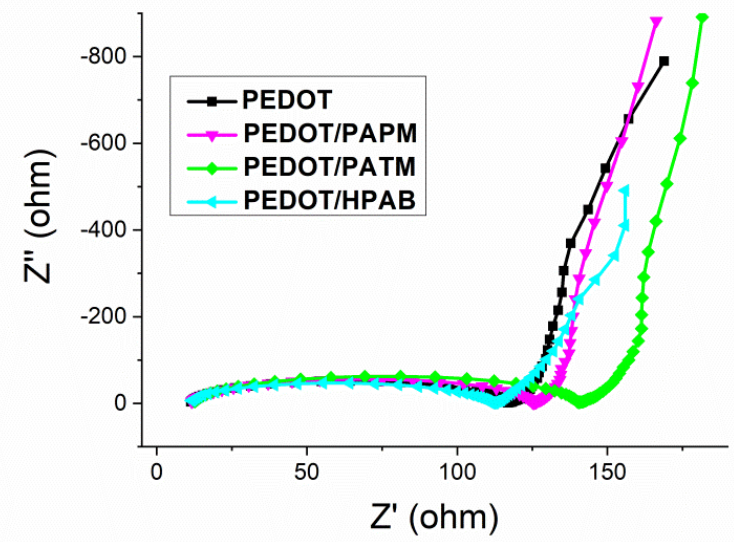

Figure 5. Nyquist plots of the PEDOT, PEDOT/PAPM, PEDOT/PATM, PEDOT/HPAB films in $1 \mathrm{M} \mathrm{LiClO}_{4}$ dissolved PC solutions.

PEDOT/ HPAB film with the smaller $R_{c t}$ value can demonstrate its easier ion traverse path at the interface between the electrode and the electrolyte. This smaller $R_{c t}$ value may be explained by the high conductivity of PEDOT/HPAB film. The above result is consistent with having a high current density in the cyclic voltammogram of PEDOT/ HPAB film. The lower $\mathrm{R}_{\mathrm{ct}}$ values displayed by PEDOT/HPAB film demonstrate that the charge-transfer process can be facilitated [37]. The powerful electrostatic interaction between the sulfonate group of HPAB and PEDOT molecules can be formed during the preparation of PEDOT/HPAB film, suggesting that the HPAB dye might be strongly attached to PEDOT film. This interaction can promote interfacial redox reaction, altering by this way the $\mathrm{R}_{\mathrm{ct}}$ value, supporting both $\mathrm{CV}$ and EIS measurements. A similar situation was observed for interaction between catechol molecule and PEDOT molecule, indicating alternations in $R_{c t}$ values [37]. However, the $R_{c t}$ values of both PEDOT/PATM and PEDOT/PAPM films are higher than PEDOT film, which can be attributed to the charge transfer resistance of the low electronic conductivity of azo dye molecule/electrolyte interface [33].

The morphologies of the Azo dyes/PEDOT and PEDOT were investigated by SEM. The SEM images of the samples in Figure 6 demonstrate that the ITO surface is covered. For 
PAPM and HPAB, the formation of granular structures on the surface is observed. The reason for increasing PAPM and HPAB surface granules is that the PEDOT coated ITO surfaces are waiting in the azo dye solution after CV measurements [38]. However, after measuring the CV of the PATM, it was observed on the ITO surface that the particles decreased compared to the others. The SEM results from the PEDOT-coated ITO surface show that better coverage of the ITO surface than PAPM, PATM, and HPAB.
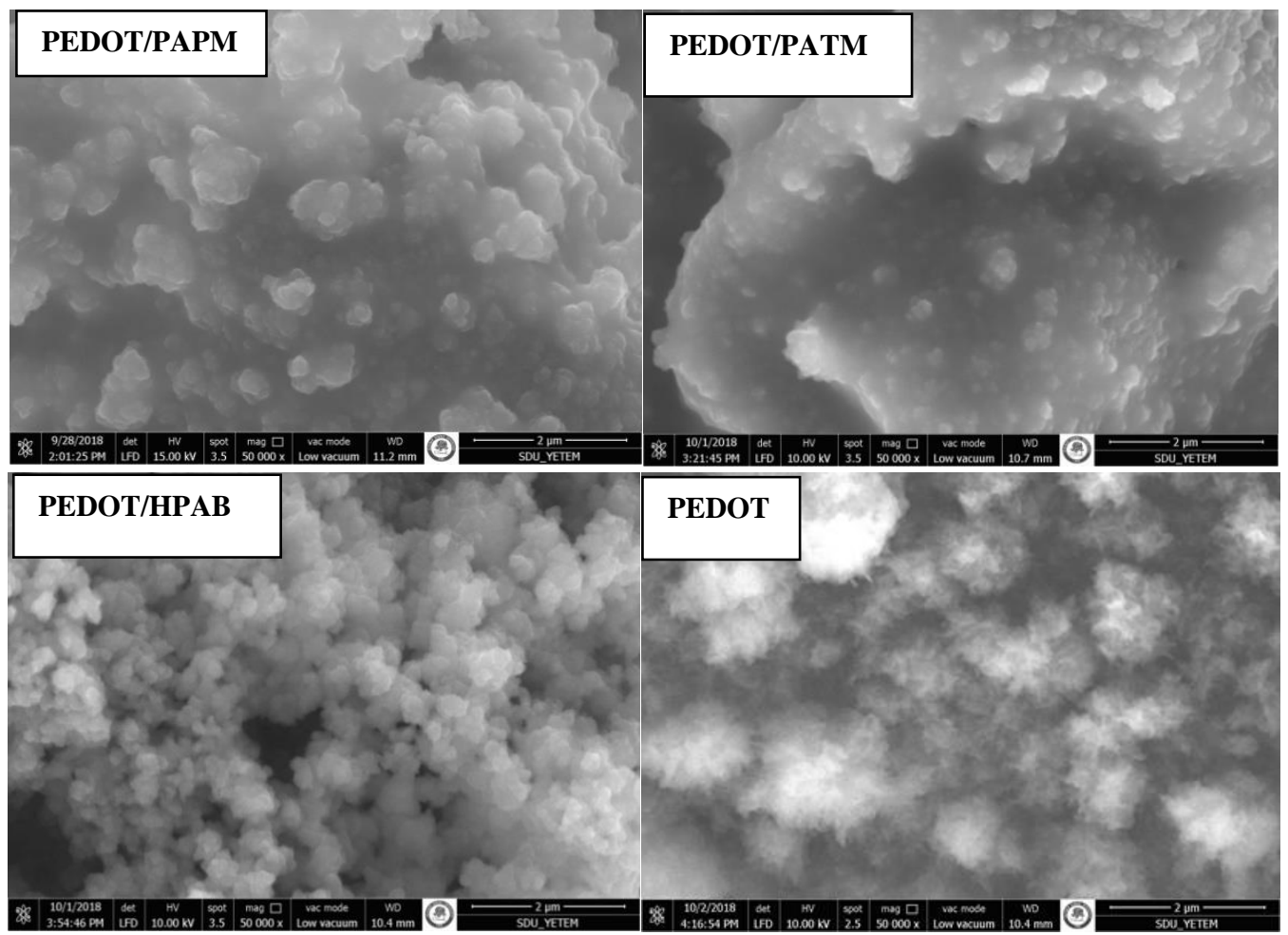

Figure 6. Structures of PEDOT prepared by a) PAPM, b) PATM, c) HPAB, and d) without azo dye.

Table 2. EDX compositions of PEDOT and azo dyes doped PEDOT composites.

\begin{tabular}{ccccc}
\hline Sample & \multicolumn{3}{c}{ Weight \% } \\
\hline & $\mathbf{C}$ & $\mathbf{O}$ & $\mathbf{N}$ & $\mathbf{S}$ \\
PAPM & 61.99 & 22.49 & 7.15 & 8.36 \\
PATM & 61.10 & 23.60 & 9.39 & 5.91 \\
HPAB & 35.26 & 54.62 & 3.09 & 7.04 \\
PEDOT & 45.83 & 39.56 & - & 14.61 \\
\hline
\end{tabular}

The EDX analysis was performed in order to approve the presence of Azo dyes (PAPM, PATM, and HPAB)/PEDOT and PEDOT on the ITO substrates. As shown in Table 2, the weight percentages of carbon, oxygen, nitrogen and sulphur in the PAPM and PATM were $61.99 \%, 22.49 \%, 7.15 \%, 8.36 \%$ and $61.10 \%, 23.60 \%, 9.39 \%, 5.91 \%$ respectively, while the contents of carbon, oxygen, nitrogen and sulphur in the HPAB were $35.26 \%, 54.62 \%$, $3.09 \%, 7.04 \%$ respectively. EDX analysis demonstrates that both PAPM, PATM and HPAB compounds well coated the surface of the ITO substrate during the electrochemical process. It has been observed that the amount of oxygen is increased, especially in HPAB. However, the nitrogen amount has decreased in the presence of HPAB in the medium.

\section{Conclusions}

In this paper, composites of PEDOT doped with different azo dyes were prepared, namely PEDOT/PAPM, PEDOT/PATM, PEDOT/HPAB, and changing of the functional group of azo dye on electrochemical properties were investigated. Cyclic voltammetry studies 
showed that electrochemical properties of PEDOT were significantly improved because of the incorporation of azo dyes as anionic dye. The EIS results indicated that PEDOT/HPAB film with the smaller $R_{c t}$ value could demonstrate its easiest ion traverse path at the interface between the electrode and the electrolyte. These results will be a source of view to the design and engineering of dye-doped CPs for significant practical application areas in material science and technology as modified electrodes.

\section{Funding}

This research received no external funding.

\section{Acknowledgments}

This research has no acknowledgment.

\section{Conflicts of Interest}

The authors declare no conflict of interest.

\section{References}

1. Skotheim, T.A.; Lelsenbaumer, R.; Reynolds, J.R. Handbook of Conducting Polymers, Conjugated Polymers: Processing and Applications. 3rd ed., CRS Press, 2006.

2. Farrage, N.M.; Oraby, A. H.; Abdelrazek, E. M. M.; Atta, D. Synthesis, characterization of Ag@PANI coreshell nanostructures using solid state polymerization method. Biointerface Res. Appl. Chem. 2019, 9, 39343941, https://doi.org/10.33263/BRIAC93.934941.

3. Abdelghany, A. M.; Meikhail, M. S.; El-Bana, A.A. Microbial activity and swelling behavior of chitosan/polyvinyl alcohol/sodium alginate semi-natural terpolymer interface containing amoxicillin for wound dressing applications. Biointerface Res. Appl. Chem. 2019, 9, 4368-4373, https://doi.org/10.33263/BRIAC95.368373.

4. Eftekhari, S.; Foroughifar, N.; Khajeh-Amiri, A.; Hallajian, S. Synthesis and characterization of polymeric nanocomposites based on poly-melamineparaformaldehyde and superparamagnetic silicon dioxide loaded Iron(III) oxide core-shell composite magnetic nanoparticles. Lett. Appl. NanoBioSci. 2020, 9, 914-918, https://doi.org/10.33263/LIANBS91.914918.

5. Tajdini, K.; Shakeri, A.; Naijian, F. Nanocomposite hydrogel of chitosan-g-poly acrylamide/ nanoclay: effect of degree of cross-linking on their swelling. Lett. Appl. NanoBioSci. 2020, 9, 995-999, https://doi.org/10.33263/LIANBS92.995999.

6. Blanchard, P.; Lerichd, P.; Frere, P.; Roncali, P. Chapter 13-Advanced Functional Polythiophene Bases on Tailored Precursors. The Hand Book of Conducting Polymers, Conjugated Polymer. CRS Press, 2006.

7. Skotheim, T.A.; Reynolds, J.R. Handbook of Conducting Polymers-Conjugated Polymers: Processing and Applications, CRC Press, Taylor and Francis 2007.

8. Barbero, C.; Salvagione, H.J.; Acevedo, D.F.; Grumelli, D.E.; Garay, F.; Planes, G.A.; Morales, G. M.; Miras, M.C. Novel synthetic methods to produce functionalized conducting polymers I. Polyanilines. Electrochim. Acta. 2004, 49, 3671-3686, https://doi.org/10.1016/j.electacta.2003.11.035.

9. Koul, S.; Chandra R. Mixed dopant conducting polyaniline reusable blend for the detection of aqueous ammonia. Sens. Actuators B Chem. 2005, 104, 57-67, https://doi.org/10.1016/j.snb.2004.04.099.

10. Saxena, V.; Malhorta, B.D. Prospects of conducting polymers in molecular electronics. Curr. Appl. Phys. 2003, 3, 293-305, https://doi.org/10.1016/S1567-1739(02)00217-1.

11. Ferreira, J.; Santos, M.L.; Ferreira, O.P.; Rubira, A.F.; Girotto, E.M. Structural and electrochromic study of polypyrrole synthesized with azo and anthraquinone dyes. J. Electroanal. Chem. 2006, 591, 27-32, https://doi.org/10.1016/j.jelechem.2006.03.016.

12. Li, L.; Zhou, J.; Wang, J.; Yang, F.; Jin, C.; Zhang, G. Anaerobic biotransformation of azo dye using polypyrrole/anthraquinonedisulphonate modified active carbon felt as a novel immobilized redox mediator. Sep. Purif. Technol. 2009, 66, 375-382, https://doi.org/10.1016/j.seppur.2008.12.019.

13. Rudd, S.; Desroches, P.; Switalska, E.; Gardner, E.; Dalton, M.; Buss, P.; Charrault, E.; Evans, D. Relationship between structure/properties of vapour deposited PEDOT and sensitivity to passive nitrate doping. Sens. Actuators B Chem. 2019, 281, 582-587, https://doi.org/10.1016/j.snb.2018.10.162. 
14. Wu, K.; Ma, J.; Cui, W.; Ruan, B.; Wu, M. The Impact of Metal Ion Doping on the Performance of Flexible Poly (3,4-ethylenedioxythiophene) (PEDOT) Cathode in Dye-Sensitized Solar Cells. J. Photoch. Photobio. A. 2017, 340, 29-34, https://doi.org/10.1016/j.jphotochem.2017.02.023.

15. Li, M.; Wang, W.; Chen, Z.; Song, Z.; Luo, X. Electrochemical determination of paracetamol based on $\mathrm{Au} @$ graphene coreshell nanoparticles doped conducting polymer PEDOT nanocomposite. Sens. Actuators B Chem. 2018, 260, 778-785, https://doi.org/10.1016/j.snb.2018.01.093.

16. Soares, A. L.; Zamora, M.L.; Marchesi, L.F.; Vidotti, M. Adsorption of catechol onto PEDOT films doped with gold nanoparticles: Electrochemical and spectroscopic studies. Electrochim. Acta. 2019, 322, https://doi.org/10.1016/j.electacta.2019.134773.

17. Yin, C.; Zhou, H.; Li, J. Influence of Doped Anions on PEDOT/Ni-Mn-Co-O for Supercapacitor Electrode Material. Appl. Surf. Sci. 2019, 464, 220-228, https://doi.org/10.1016/j.apsusc.2018.09.028.

18. Harris, A.R.; Molino, P.J.; Paolini, A.G.; Wallace, G.G. Effective Area and Charge Density of Chondroitin Sulphate Doped PEDOT Modified Electrodes. Electrochim. Acta. 2016, 197, 99-106, https://doi.org/10.1016/j.electacta.2016.03.038.

19. Fleischmann, C.; Lievenbrück, M.; Ritter, H. Polymers and Dyes: Developments and Applications. Polymers, 2015, 7, 717-746, https://doi.org/10.3390/polym7040717.

20. Bessegato, G.G.; Brugnera, M.F.; Zanoni, M.V.B. Electroanalytical sensing of dyes and colorants. Curr Opin Electrochem. 2019, 16, 134-142, https://doi.org/10.1016/j.coelec.2019.05.008.

21. Eiras, C.; Zucolotto, V.; Oliveira, O.N.; Goncalves, D. Electrochemical synthesis of polypyrrole-azo dyes composite films. Synth. Met. 2003, 135-136, 161-162, https://doi.org/10.1016/S0379-6779(02)00516-7.

22. Koshido, T.; Kawai, T.; Yoshino, K. Novel photomemory effects in photochromic dye-doped conducting polymer and amorphous photochromic dye layer. Synth. Met. 1995, 73, 257-260, https://doi.org/10.1016/0379-6779(95)80023-9.

23. Feng, W.; Fujii, A.; Lee, S.; Wu, H.C.; Yoshino, K. Electrical and optical properties of new soluble conducting polymer/dye composite and junction device. Synth. Met. 2001, 121, 1595-1596, https://doi.org/10.1016/S0379-6779(00)01502-2.

24. Gupta, N.; Sharma, S.; Mir, I.A.; Kumar, D. Advances in sensors based on conducting polymers. J. Sci. Ind. Res. India. 2007, 65, 549-557.

25. Ngamna, O.; Moulton, S.E.; Wallace, G.G. Incorporation of dye into conducting polyaniline nanoparticles. React. Funct. Polym. 2007, 67, 173-183, https://doi.org/10.1016/j.reactfunctpolym.2006.10.007.

26. Sefer, E.; Koyuncu, F.B., Oguzhan, E. A New Near- Infrared Switchable Electrochromic Polymer and Its Device Application. J. Polym. Sci. 2010, 48, 4419-4427, https://doi.org/10.1002/pola.24229.

27. Sachin, K.M.; Karpe, S.A.; Singh, M.; Bhattarai, A. Self-assembly of sodium dodecylsulfate and dodecyltrimethylammonium bromide mixed surfactants with dyes in aqueous mixtures. R. Soc. Open Sci. 2019, 6, https://doi.org/10.1098/rsos.181979.

28. Fabretto, M.; Autere, J.P.; Hoglinger, D. Vacuum vapour phase polymerized poly(3,4ethylenedioxythiophene) thin films for use in large-scale electrochromic devices. Thin Solid Films, 2011, 519, 2544-2549, https://doi.org/10.1016/j.tsf.2010.12.016.

29. Kim, E. Effects of Binary Doping on Chiroptical, Electrochemical, and Morphological Properties of Chiral Polyaniline. Journal of the Korean Chemical Society 2015, 595, 423-428.

30. Li, Z.; Ye, B.; Hu, X.; Ma, X.; Zhang, X.; Deng, Y. Facile electropolymerized-PANI as counter electrode for low cost dye-sensitized solar cell. Electrochem. Commun. 2009, 11, 1768-1771, https://doi.org/10.1016/j.elecom.2009.07.018.

31. Bai, X.; Wang, X.; Li, B. Capacitive behavior and material characteristics of congo red doped poly (3,4ethylene dioxythiophene). Electrochim. Acta. 2018, 283, 590-596, https://doi.org/10.1016/j.electacta.2018.07.004.

32. Liu, F. Electrodeposition of manganese dioxide in three-dimensional poly(3,4 ethylenedioxythiophene)poly(styrene sulfonic acid)-polyaniline for supercapacitor. J. Power Sources. 2008, 182, 383-388, https://doi.org/10.1016/j.jpowsour.2008.04.008.

33. Cheng, Q.; Meng, C.; Qian, Y.; He, J.; Don, X. Energy capacity enhancement of all-organic fabric supercapacitors by organic dyes: Old method for new application. Prog. Org. Coat. 2020, 138, https://doi.org/10.1016/j.porgcoat.2019.105439.

34. Liang, F.; Li, X.; Zhang, D. Electrochromic Properties of Acid Dye Doped Poly(3,4 ethylenedioxythiophene) by Electropolymerization. J. Nanosci. Nanotechnol. 2015, 15, 3130-3134, https://doi.org/10.1166/jnn.2015.9648.

35. Tavoli, F.; Alizadeh, N. In situ UV-vis spectroelectrochemical study of dye doped nanostructure polypyrrole as electrochromic film. J. Electroanal. Chem. 2014, 720-721, 128-133, https://doi.org/10.1016/j.jelechem.2014.03.022.

36. Rozman, M.; Bren, U.; Lukṡić, M.; Godec, R.F.; Kalarakis, A.N.; Stathatos, E. Electrochromic cell with hydrogel-stabilized water-based electrolyte using electrodeposition as a fast color changing mechanism. Electrochim. Acta. 2018, 283, 1105-1114, https://doi.org/10.1016/j.electacta.2018.07.052. 
37. Soares, A.L.; Zamora, M.L.; , Marchesi, L.F.; Vidotti, M. Adsorption of catechol onto PEDOT films doped with gold nanoparticles: Electrochemical and spectroscopic studies. Electrochim. Acta. 2019, 322, https://doi.org/10.1016/j.electacta.2019.134773.

38. Khosravi, R.; Hossini, H. Electrochemical Decolorization of Reactive Dye from Synthetic Wastewater by Mono-Polar Aluminum Electrodes System. Int. J. Electrochem. Sci. 2017, 12, 4745-4755, https://doi.org/10.20964/2017.06.75. 


\section{Supporting Information}
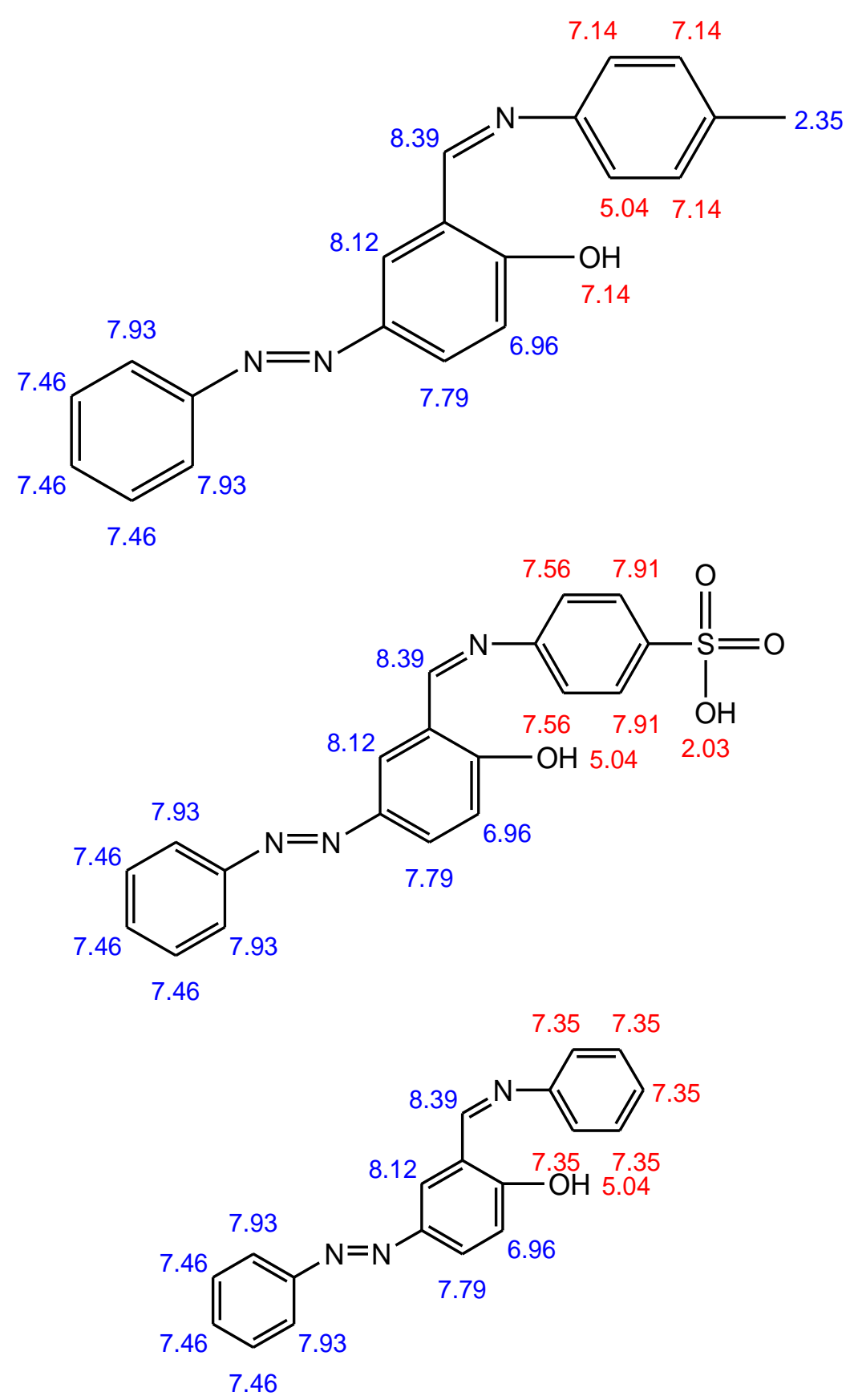

Figure S1. NMR shifts (ppm) 